\title{
In-situ kinetic and thermodynamic study of 2,4-dichlorophenoxyacetic acid adsorption on molecularly imprinted polymer based solid-phase microextraction coatings
}

\author{
Xiaoxia Yang ${ }^{a}$, Turghun Muhammad ${ }^{\mathrm{a}, *}$, Jingjing Yang ${ }^{\mathrm{a}}$, Ayzukram Yasen ${ }^{\mathrm{a}}$, \\ Lingxin Chen ${ }^{\mathrm{b}, \mathrm{c}}$ \\ a Key Laboratory of Energy Materials Chemistry, Ministry of Education, Key Laboratory of Advanced Functional Materials, Autonomous Region, Institute of \\ Applied Chemistry, College of Chemistry, Xinjiang University, Urumqi, 830046, Xinjiang, PR China \\ ${ }^{\mathrm{b}}$ CAS Key Laboratory of Coastal Environment Processes and Ecological Remediation, Yantai Institute of Coastal Zone Research, Chinese Academy of Sciences, \\ Yantai 264003, PR China \\ ' School of Chemistry and Chemical Engineering, Yantai University, Yantai 264005, PR China
}

\section{A R T I C L E I N F O}

\section{Article history:}

Received 2 April 2020

Received in revised form 30 June 2020

Accepted 30 June 2020

Available online 17 July 2020

\section{Keywords:}

Adsorption kinetics

Adsorption thermodynamics

2,4-Dichlorophenoxyacetic acid

Molecularly imprinted polymer

SPME coating

Fiber-optic sensing

\begin{abstract}
A B S T R A C T
Solid-phase microextraction (SPME) is attracting increasing interest due to being promising, new and green sample-preparation technique. Despite the vast research on the SPME, little is known about adsorption kinetics and thermodynamics of SPME coating, which plays the key role in the extraction. In this paper, a blade type SPME coating was prepared on glass slide, and 2,4-dichlorophenoxyacetic acid (2,4D) adsorption on the coating were monitored by in-situ fiber-optic sensing. The effects of contact time, temperature (298-318 K) and initial concentration $(20-150 \mathrm{mg} / \mathrm{L})$ of 2,4-D on the adsorption properties of SPME coating were discussed. The results demonstrated that the pseudo-second-order model was most suitable for describing 2,4-D adsorption on the SPME coating. The thermodynamic parameters $(\Delta H, \Delta S$, $\Delta G$ ) indicate that 2,4-D adsorption at low concentration by the SPME coating is exothermic and spontaneous process. Under the same conditions, the molecularly imprinted polymers (MIPs) coating have significantly higher adsorption capacity, and faster adsorption rate than the non-imprinted polymers (NIPs) SPME coating. This approach provides a tool for in-situ monitoring of adsorption kinetics and thermodynamics of SPME coating which requires fast measurement and small volume.
\end{abstract}

(ㄷ) 2020 Elsevier B.V. All rights reserved.

\section{Introduction}

2,4-dichlorophenoxyacetic acid (2,4-D) is used as a herbicide and plant growth regulator in agriculture, such as in rice and wheat due to its low-cost [1,2]. However, 2,4-D has been testified to be toxic to human body, according to the World Health Organization (WHO). The maximum concentration of 2,4-D in drinking water should not more than $70 \mu \mathrm{g} / \mathrm{L}[3,4]$. In addition, 2,4-D has been detected in water bodies all over the world and found to be hardly degradable.

At present, 2,4-D has been determined mainly by high performance liquid chromatography (HPLC), immunoassays [5], gas chromatography (GC) [6], gas chromatography-mass spectrometry (GC-MS) [7], and liquid chromatography-mass spectrometry

\footnotetext{
* Corresponding author.

E-mail address: turghunm@xju.edu.cn (T. Muhammad).
}

(LC-MS) [8]. The sample matrix is often very complex, and the 2,4-D concentration is very low. It is usually necessary to separate and enrich the low concentration of 2,4-D in the samples. Solid-phase microextraction (SPME) has been applied increasingly for sample preparation due to its easy miniaturization, automation of devices, and its convenience in coupling with chromatographic instruments [9-11]. Ideally, SPME coatings possess high adsorption capacity, selectivity and fast kinetics, as well as high stability. Commercial SPME coatings include polyacrylate (PA), polydimethylsiloxane (PDMS), divinylbenzene (DVB), carbowax/divinylbenzene (CW/DVB), divinylbenzene/carboxen/polydimethylsiloxane (DVB/CAR/PDMS) and carboxen (CAR) [12]. However, these are common coatings used for a broad range of analytes with different polarity, almost without any specificity. And they also suffer from poor stability due to physical attachment on the substrate $[13,14]$. Chemical immobilization can be a good alternative to address this limitation. Polymer coatings prepared by sandwich method have good physical robustness, 
controllable thickness, thermal stability and reusability. Molecularly imprinted polymers (MIPs) is a kind of material for selective recognition of target molecules [15-17], and have been widely used in sample pretreatment due to their high selectivity and low cost $[18,19]$. Although extensive research has been carried out on SPME coating materials, there are few studies that have systematically investigated their adsorption characteristics.

Fiber-optic sensing technology has been increasingly used in the fields of energy, environmental protection, industrial control, medicine and health and construction [20,21]. Fiber-optic sensor has the advantages of being in-situ, real-time and fast response [22]. Compared with the traditional manual sampling method, the fiberoptic sensing in-situ detection method is labor-saving, simple and highly accurate. The traditional manual sampling method can cause the solution loss and affect the measurement accuracy. The in-situ fiber-optic detection method can address all of these problems.

In this study, a blade type SPME coating was successfully prepared on the glass slides via covalent bonding using molecular imprinting techniques. In-situ fiber-optic sensing was presented for continuously real-time monitoring of 2,4-D adsorption process on the MIPs and NIPs coatings.

\section{Materials and methods}

\subsection{Materials}

Ethylene glycol dimethacrylate (EGDMA), 2,2-azobis isobutyronitrile (AIBN), 3-(Methacryloyloxy) propyltrimethoxysilane (MPS) and 2,4-dichlorophenoxyacetic acid (2,4-D), 2,4dichlorophenylacetic acid (DPAc), 4-chloroxyphenylacetic acid (CPOAc) and 4-chlorphenylacetic acid (CPAc) were purchased from the Tokyo Chemical Industry Co. Ltd. (Shanghai, China). Analytical grade methanol and ethanol were obtained from Sinopharm Chemical Reagent Co., Ltd. (Shanghai, China). 4-vinyl pyridine (4-VP) was purchased from J\&K Chemicals (Beijing, China). Polytetrafluoroethylene (PTFE) microporous membranes were obtained from Shanghai Xingya Purifying Material Factory (Shanghai, China). Glass sides were obtained from Zhejiang Yixing Glass Instrument Factory (Zhejiang, China). Ultrapure water was obtained from a purification system (Chengdu, China).

\subsection{Instrumentation}

The absorption spectrum was gained with an in-situ fiber-optic sensing detection system (Ocean Optics, Dunedin, Florida, USA). The system consists of a stable and continuous source of spectrum light (195-644 nm) which was provided by a DH-2000 deuterium tungsten halogen source. An HR2000 charge-coupled device spectrophotometer was connected to the light source by a fiber-optic dipping probe. The probe includes an Al-coated mirror, an illumination fiber, and all mounted in stainless steel cylinders. An adsorption vessel was assembled from a conical flask, a heating magnetic stirrer, an adsorption bag, and a fiber-optic probe. The heating magnetic stirrer was obtained from IKA (Germany). The ultrasonic cleaner was obtained from Kunshan City Ultrasonic Instrument Co. Ltd. (KQ5200E, Kunshan, China).

\subsection{Polymer coating preparation}

The polymer coating was prepared through a novel sandwich method with modified glass slide as substrate and a microporous membrane as support material. The detailed preparation process of polymer coating was described in the supplementary materials. Fig. A. 1 shows a schematic illustration of the preparation of the polymer coating.

\section{Experimental method}

\subsection{Stock solution}

Preparation of 2,4-D $500 \mathrm{mg} / \mathrm{L}$ stock solution was accomplished by accurately weighting of standard sample and completely dissolving in methanol, and then the volume was fixed with ultrapure water. The stock solution was stored in a refrigerator for later use.

\subsection{Calibration curve}

The stock solution was diluted with methanol-water (v/v, 1:9) to obtain a series of 2,4-D calibration solutions in the range of $5-200 \mathrm{mg} / \mathrm{L}$. The different concentrations of 2,4-D solution were detected by the in-situ fiber-optic spectrophotometer at $283 \mathrm{~nm}$ according to the following procedure:

(1) The deuterium lamp of the fiber-optic light source was opened and preheated for $30 \mathrm{~min}$;

(2) The spectra suite software was turned on, fiber-optic probe was immersed into solvent (as reference) and bubbles in probe window were removed;

(3) The integration time and smoothing width were adjusted to $24 \mathrm{~ms}$ and 5 , respectively. The light intensity level was adjusted around 3200 counts at the $283 \mathrm{~nm}$ (detection wavelength), and the signal intensity, reference and dark spectra were stored;

(4) The fiber-optic probe with light-path of $5 \mathrm{~mm}$ was immersed into the vessels containing $3 \mathrm{~mL}$ of 2,4 -D solution with different concentrations, respectively. Then, obtain the absorbance of each 2,4-D solution was obtained.

The same system configuration described above was used in the rest of the work.

\subsection{Batch experiments}

Four pieces of SPME coatings were placed in a vial and soaked in methanol-water ( $v / v, 1: 9)$ for $1 \mathrm{~h}$ to activate the coatings. The fiberoptic probe was dipped in 2,4-D solution of different concentrations and the instrument parameters were adjusted. The activated four pieces of SPME coatings were put into the adsorption solution as shown in picture Fig. A.2, and the adsorption was carried out at $200 \mathrm{rpm}$ and $298 \mathrm{~K}$. If the absorbance of adsorbate does not change more than 0.002 within $30 \mathrm{~min}$, it was considered that the process reached adsorption apparent equilibrium stage. Finally, the light source was turned off and stored the experimental data. Through the above experimental method, the adsorption behavior of 2,4-D with different concentrations (20-150 mg/L) on SPME coatings was monitored at $298-318 \mathrm{~K}$. The adsorption isotherm was obtained by using the relative equilibrium concentration $C_{\mathrm{e}}(\mathrm{mg} / \mathrm{L})$ as abscissa and the adsorption capacity $Q_{e}(\mathrm{mg} / \mathrm{g})$ as ordinate. The adsorption and desorption capacity of 2,4-D were calculated by the following equations:

$Q_{e}=\frac{\left(C_{0}-C_{e}\right)}{m} V_{i}$

$D_{e}=\frac{C_{d}}{m} V_{d}$

where $C_{0}$ and $C_{\mathrm{e}}$ are the initial and the relative equilibrium concentrations of the sample solutions $(\mathrm{mg} / \mathrm{L}) ; V_{\mathrm{i}}$ indicates the total volume of the sample solution used in the study (L); $C_{\mathrm{d}}$ and $V_{\mathrm{d}}$ are the concentration $(\mathrm{mg} / \mathrm{L})$ and volume $(\mathrm{L})$ of the desorption solution of 2,4-D. $\mathrm{m}$ is the weight of the polymer $(\mathrm{g})$; $Q_{\mathrm{e}}$ stands for the adsorption capacity at adsorption equilibrium ( $\mathrm{mg} / \mathrm{g}$ ); $D_{\mathrm{e}}$ is the desorption capacity when desorption reaches relative equilibrium ( $\mathrm{mg} / \mathrm{g})$. 


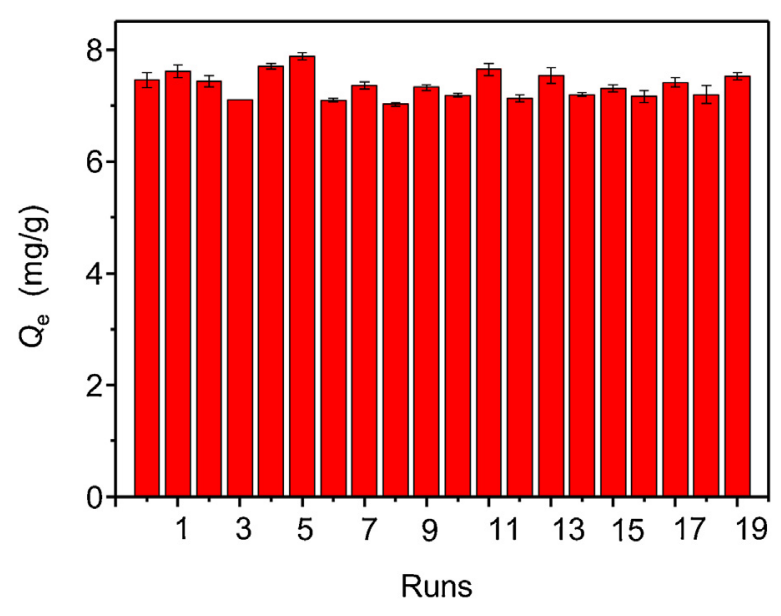

Fig. 1. Reusability of MIPs coating.

\section{Results and discussion}

\subsection{Stirring speed}

In order to investigate the effect of stirring speed on adsorption capacity of the SPME coating, the magnetic stirring speeds of 100 , 200 and $300 \mathrm{rpm}$ were selected to investigate the effect of stirring speed on the adsorption by in-situ measurement. Fig. A.4 provides an overview in the time of $250 \mathrm{~min}$, with the increasing of agitation speed, the adsorption capacity increases, which may be due to good stirring makes the solution distribute more uniformly [23]. When the stirring speed increases from $200 \mathrm{rpm}$ to $300 \mathrm{rpm}$, the adsorption capacity of SPME coating changes little. However, the surface of the SPME coatings will be destroyed if the mixing speed is too fast, and it is also a challenge to the fixing of the SPME coatings in the vial. Therefore, $200 \mathrm{rpm}$ was selected for rest of the study.

\subsection{Regeneration performance of SPME coating}

To be an effective SPME device, the regeneration and reuse of SPME coating are essential. Under the same conditions, adsorptiondesorption experiments were repeated on the fiber-optic sensing detection system. As shown in Fig. A.5, the relative standard deviation (RSD) value of adsorption capacity at the same time point of three groups of parallel experiments was $1.78 \%$. In this study, the MIPs coatings were regenerated by extraction using $10 \%$ acetic acid-methanol. In addition, as shown in Fig. 1, the adsorption capacity of MIPs did not change significantly after 19 runs (RSD less than $3.2 \%$ ), indicating that MIPs coating had outstanding stability and repeatability. Therefore, the MIPs coatings have good regeneration ability and can be used as a good SPME material for the separation and enrichment of trace 2,4-D in environmental samples.

\subsection{Adsorption kinetics}

\subsubsection{Adsorption kinetic curves}

The adsorption kinetic curves of 2,4-D on different SPME coatings obtained by the system at $298 \mathrm{~K}$ are shown in Fig. 2 (a) and Fig. A.6. With the increasing of 2,4-D concentration, the mass transfer enhances, then the SPME coating adsorption capacity increases gradually, and the relative adsorption equilibrium time gets longer. The adsorption capacity rapidly increases in the initial $40 \mathrm{~min}$. In the beginning of the adsorption, interaction opportunity between solute and solvent is the largest, which makes the adsorption rate is the fastest in this stage. With the extension of adsorption time, the adsorption rate decreases and desorption rate increases. As detailed in Fig. 2 (b), under the same conditions, adsorption capacity of MIPs coating is higher than that of NIPs coating for 2,4-D. That is due to the contribution of imprinted binding sites, which was formed during the polymerization around template and the binding sites have complementary shape and size with 2,4-D molecules [24]. 2,4-D and its analogues DPAc, CPOAc and CPAc were used to investigate the selective adsorption of SPME coating. As shown in Fig. 2 (c), both MIPs and NIPs adsorbed 2,4-D and its structural analogues, but the adsorption capacity was different. It was observed that MIPs coating had the greatest binding capacity to 2,4-D compared with its analogues. This is due to MIPs has high specificity and selectivity to 2,4-D resulted from a remarkable imprinting effect.

\subsubsection{Adsorption kinetic models}

Adsorption rate is one of the main focuses of adsorption kinetics, which plays an extremely significant role in the whole adsorption process [25]. The adsorption process is clearly described by three kinds of kinetic models, and the equations of these kinetic models were as follows.

Pseudo-first-order model [26]:

$$
\ln \left(Q_{e}-Q_{t}\right)=\ln Q_{e}-K_{1} t
$$

Pseudo-second-order model [27]:

$\frac{t}{Q_{t}}=\frac{1}{K_{2} Q_{e}^{2}}+\frac{t}{Q_{e}}$

Intra-particle diffusion model [28]:

$t_{1 / 2}=\frac{1}{K_{3} Q_{e}}+C$

where $Q_{e}$ and $Q_{t}$ are the adsorption capacities $(\mathrm{mg} / \mathrm{g})$ at equilibrium and at a time $t$, respectively. $K_{1}, K_{2}$ and $K_{3}$ are pseudo-first-order rate constant $(1 / \mathrm{min})$, pseudo-second-order rate constant ( $\mathrm{g} /(\mathrm{mg} \cdot \mathrm{min})$ and intra-particle diffusion rate constant $\left(\mathrm{mg} /\left(\mathrm{mL} \cdot \mathrm{min}^{1 / 2}\right)\right), t_{1 / 2}$ is the time required to complete half of the adsorption, $\mathrm{C}$ is the intra-particle diffusionmodel constant.

The fitting curves of pseudo-first-order and pseudo-secondorder models of 2,4-D adsorption on NIPs and MIPs coatings are shown in Fig. 3 (a) and (b). The parameters of the two models are listed in Table 1 . Table 1 shows that the $R^{2}$ values $\left(R_{\text {NIPs }}{ }^{2}=0.8943\right.$, $\left.\mathrm{R}_{\mathrm{MIPs}}{ }^{2}=0.9635\right)$ of pseudo-first-order model was smaller than that of pseudo-second-order model $\left(\mathrm{R}_{\mathrm{NIPs}}{ }^{2}=0.9927, \mathrm{R}_{\mathrm{MIPs}}{ }^{2}=0.9983\right)$. In addition, under different initial concentration conditions $\left(C_{0}\right)$, the theoretical value of equilibrium adsorption capacity $\left(Q_{\text {cal }}\right)$ calculated by the pseudo-first-order model was considerably different from the experimental adsorption capacity ( $Q_{\exp }$ ) obtained from the experiments (error was 34.94-66.36\%). However, the error between the theoretical value of $Q_{c a l}$ from the pseudo-secondorder model and the $Q_{\text {exp }}$ was less than $10 \%$. High correlation coefficient and low error values indicate that the pseudo-secondorder model can more accurately describe the adsorption behavior of 2,4-D on MIPs and NIPs coatings [29].

The adsorption kinetics of 2,4-D on MIPs and NIPs coatings are controlled by the adsorption mechanism and intra-particle diffusion rate. As identified from Fig. 3 (c), the plots of $Q_{e}$ versus $t_{1 / 2}$ don't give straight line within whole adsorption process, but represent a multicollinearity, which indicates that two or more stages exist in the adsorption of 2,4-D on MIPs. It can be explained that adsorption process is carried out in three consecutive steps [30]: (1) Instantaneous adsorption of adsorbate on the surface of adsorbent, (2) diffusion of adsorbate molecules in adsorbent pores, (3) adsorption of adsorbate molecules on the inner surface of the adsorbent. Adsorption of 2,4-D on MIPs and NIPs coatings can be divided into three stages, none of the three fitted lines can pass through the origin point of the coordinate. This indicates that the intra-particle diffusion is not the only speed limiting step, and the process can also be controlled by external mass transfer and internal diffusion 

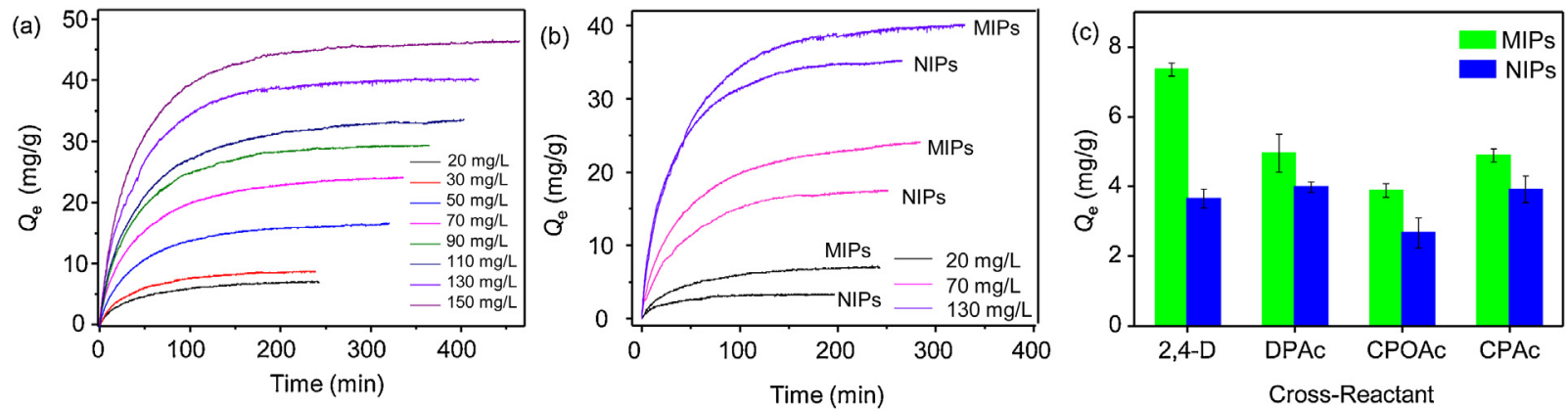

Fig. 2. Adsorption kinetic curves of 2,4-D on different SPME coatings at $298 \mathrm{~K}$ (a) MIPs (b) MIPs and NIPs (c)Selectivity adsorption of SPME coating of MIPs and NIPs.
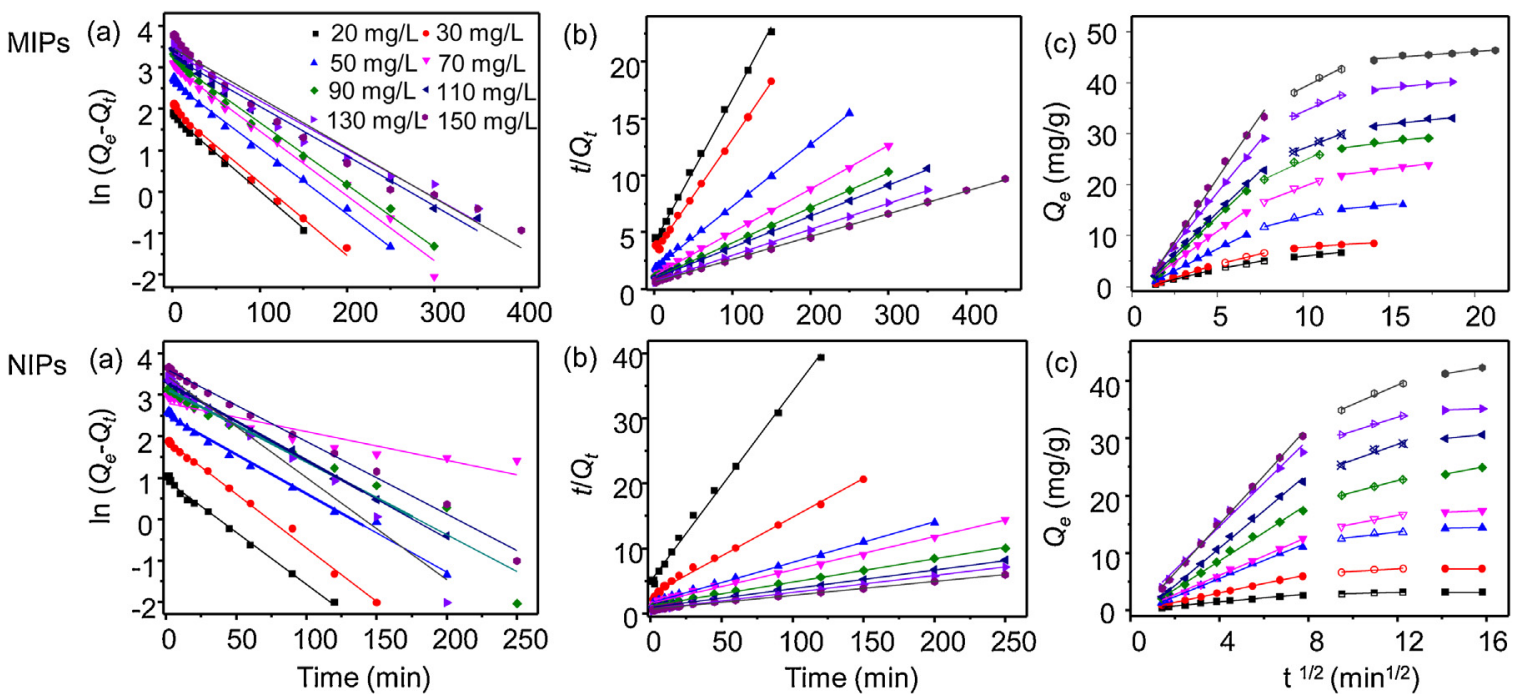

Fig. 3. Fitting plots of adsorption kinetic models to 2,4-D on SPME coatings (a) pseudo-first-order (b) pseudo-second-order (c) Intra-particle diffusion.

Table 1

Kinetic parameters of pseudo-first-order and pseudo-second-order models for 2,4-D on NIPs and MIPs SPME coatings.

\begin{tabular}{|c|c|c|c|c|c|c|c|c|}
\hline Adsorbent & $C_{0}(\mathrm{mg} / \mathrm{L})$ & $Q_{\exp }(\mathrm{mg} / \mathrm{g})$ & $\begin{array}{l}\text { Pseudo-first-order } \\
Q_{\text {cal }}(\mathrm{mg} / \mathrm{g})\end{array}$ & $\mathrm{K}_{1} \times 10^{2}(1 / \mathrm{min})$ & $\mathrm{R}^{2}$ & $\begin{array}{l}\text { Pseudo-second-order } \\
Q_{\text {cal }}(\mathrm{mg} / \mathrm{g})\end{array}$ & $\mathrm{K}_{2} \times 10^{4}(\mathrm{~g} /(\mathrm{mg} \cdot \mathrm{min})$ & $\mathrm{R}^{2}$ \\
\hline \multirow{8}{*}{ MIPs } & 20 & 7.02 & 4.14 & 1.79 & 0.9931 & 7.56 & 37.8627 & 0.9977 \\
\hline & 30 & 8.73 & 4.70 & 1.75 & 0.9897 & 9.11 & 29.4021 & 0.9983 \\
\hline & 50 & 16.43 & 7.81 & 1.58 & 0.9958 & 18.08 & 16.0191 & 0.9991 \\
\hline & 70 & 23.98 & 10.63 & 1.56 & 0.9888 & 26.25 & 12.1230 & 0.9987 \\
\hline & 90 & 29.42 & 11.81 & 1.5 & 0.9934 & 32.57 & 9.5182 & 0.9998 \\
\hline & 110 & 33.53 & 12.58 & 1.19 & 0.9864 & 36.36 & 8.0926 & 0.9996 \\
\hline & 130 & 40.81 & 13.73 & 1.16 & 0.9635 & 43.86 & 7.7139 & 0.9994 \\
\hline & 150 & 46.37 & 14.92 & 1.2 & 0.968 & 49.75 & 6.7696 & 0.9996 \\
\hline \multirow{8}{*}{ NIPs } & 20 & 3.18 & 2.07 & 2.51 & 0.9944 & 3.43 & 171.0975 & 0.9950 \\
\hline & 30 & 7.42 & 4.42 & 2.59 & 0.9963 & 7.39 & 50.6258 & 0.9927 \\
\hline & 50 & 14.57 & 7.01 & 1.89 & 0.9916 & 16.16 & 23.2543 & 0.9989 \\
\hline & 70 & 21.47 & 8.85 & 0.69 & 0.8943 & 19.61 & 16.6358 & 0.9938 \\
\hline & 90 & 25.04 & 11.57 & 1.76 & 0.9510 & 27.70 & 11.2725 & 0.9976 \\
\hline & 110 & 30.61 & 13.01 & 1.88 & 0.9976 & 33.72 & 9.0442 & 0.9989 \\
\hline & 130 & 34.98 & 14.85 & 2.47 & 0.9764 & 38.46 & 11.8972 & 0.9990 \\
\hline & 150 & 42.63 & 16.86 & 1.75 & 0.9929 & 46.29 & 6.9100 & 0.9974 \\
\hline
\end{tabular}

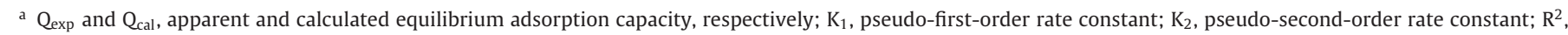
correlation coefficient.

of particles. The values of $\mathrm{K}_{\mathrm{id} 1}, \mathrm{~K}_{\mathrm{id} 2}, \mathrm{~K}_{\mathrm{id} 3}$, and $\mathrm{C}_{1}, \mathrm{C}_{2}, \mathrm{C}_{3}$ in the adsorption process are summarized in Table A.1. According to Fig. 3 (c) and table A.1, the adsorption rates of 2,4-D on MIPs and NIPs coatings are obviously different. In the first and second step, the adsorption of 2,4-D on the MIPs coatings is faster. In the third step, the low free concentration of 2,4-D and the very limited adsorption sites of coating result in a relative equilibrium. However, the adsorption on the MIPs coatings is still growing. Great number of recognition sites of MIPs coatings are attributed to higher specific adsorption capac- ity against 2,4-D. The main specific interactions of the MIPs SPME coating are resulted from ionic bonds and hydrophobic interactions [31].

\subsection{Adsorption thermodynamics}

An adsorption isotherm is a method to measure the relationship between the equilibrium concentrations and adsorption capacity when adsorption reaches dynamic equilibrium in a certain concen- 

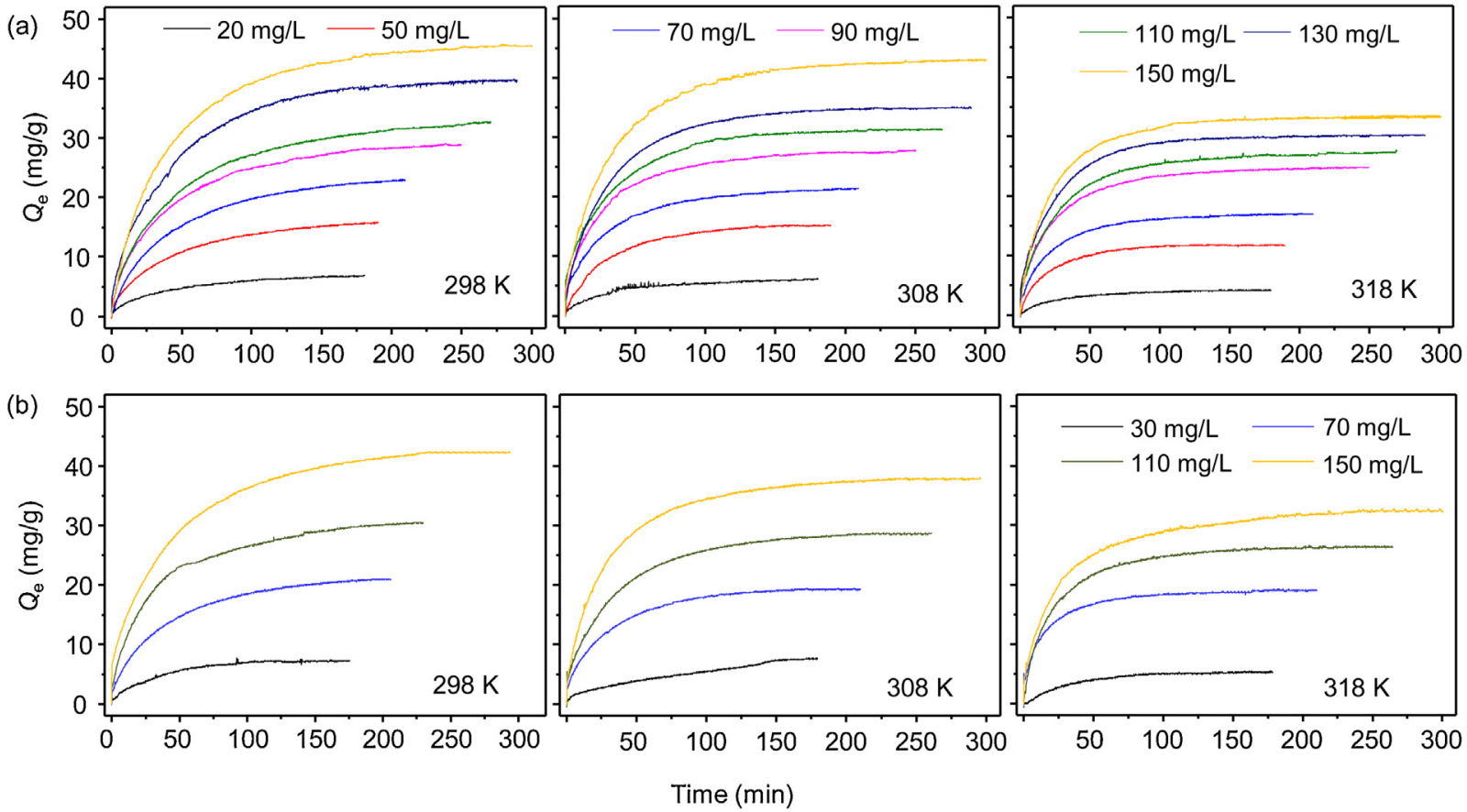

Fig. 4. Adsorption kinetics of 2,4-D on polymer coatings at different temperatures (a) MIPs (b) NIPs.

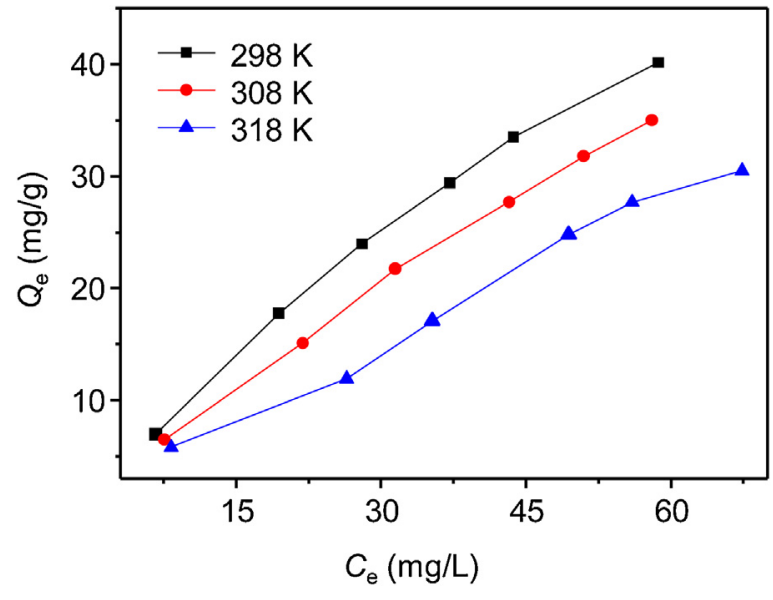

Fig. 5. Adsorption isotherms of 2,4-D on MIPs SPME coatings.

tration range [32]. At 298, 308 and $318 \mathrm{~K}$, the adsorption process of 2,4-D on SPME coatings were monitored by in-situ fiber-optical spectrometer, and the adsorption capacity was calculated according to equation (1). The adsorption kinetics of MIPs and NIPs coatings for 2,4-D at different temperatures are illustrated in Fig. 4. The adsorption isotherms were obtained using the equilibrium concentration as horizontal coordinate and adsorption amount as vertical coordinate (Fig. 5). The adsorption capacity of 2,4-D increases with the increasing of concentration. With the increasing of temperature, the adsorption capacity of the MIPs coating decreases. Generally, low temperature is favorable for the adsorption.

Langmuir model is an adsorption isotherm model based on the basis of kinetics viewpoint. This theory has assumptions that [33] (1) the adsorption takes place on the monolayer of the adsorbent, and only one molecule is adsorbed at each adsorption site, (2) there is no interaction between the adsorbed molecules, (3) the enthalpy values of all adsorbed molecules are equal. Langmuir isotherm model was determined as [34]:

$\frac{1}{Q_{e}}=\frac{1}{K_{L} Q_{\max }} \frac{1}{C_{e}}+\frac{1}{Q_{\max }}$

Freundlich isotherm model is one of the empirical equations for heterogeneous adsorbents. The adsorption energy of each site is different. It is assumed that (1) the adsorption heat decreases with the increase of the coverage area of the adsorbent, (2) the adsorption points on the adsorbent surface have different adsorption energies. The Freundlich equation is determined as follows:

$\ln Q=\ln K_{F}+\frac{1}{n} \ln C_{e}$

The basic characteristics of adsorption isotherms can be expressed by the separation factor $\left(R_{\mathrm{L}}\right)$. The $R_{\mathrm{L}}$ is expressed as [35]:

$R_{L}=\frac{1}{1+K_{L} C_{0}}$

In these equations, $Q_{e}$ and $Q_{\max }$ are the equilibrium adsorption capacity and maximum adsorption capacity ( $\mathrm{mg} / \mathrm{g}$ ), respectively. $C_{\mathrm{e}}$ is the concentration of solution when the adsorption reaches relative equilibrium $(\mathrm{mg} / \mathrm{L}) . \mathrm{K}_{\mathrm{L}}$ is the Langmuir constant $(\mathrm{L} / \mathrm{mg})$, $K_{F}$ is the Freundlich constant or the value of $Q_{e}$ at $C_{e}=1 \mathrm{mg} / \mathrm{L}$ $(\mathrm{mg} / \mathrm{g}) \cdot(\mathrm{L} / \mathrm{mg})^{1 / \mathrm{n}} \cdot \mathrm{n}$ is the heterogeneous factor related to the adsorption intensity. $R_{\mathrm{L}}$ is the separation factor. $R_{\mathrm{L}}=0$, the adsorption process is irreversible. $R_{\mathrm{L}}=1$, the adsorption process is linear. If $R_{\mathrm{L}}>1$, the adsorption process is unfavorable. $0<R_{\mathrm{L}}<1$, the SPME coating is favorable for 2,4-D adsorption.

The curves of isotherm models are presented in Fig. A.7. Table 2 summarizes the isotherm parameters of 2,4-D adsorption, comparing $R^{2}$ of the two isotherm models, Langmuir model is more suitable for the isothermal adsorption data of NIPs. The results indicate that the adsorption of the NIPs coating for 2,4-D could be a single molecular layer adsorption. But the Langmuir model is better than Freundlich model in fitting 2,4-D isotherm adsorption data of MIPs at low temperature according to the values of $R^{2}$. At the higher temperature, the Freundlich model is more suitable for isotherm adsorption data with the increase of temperature. From Table 2, it 
Table 2

Langmuir and Freundlich isotherm constants of 2,4-D on SPME coatings. ${ }^{\mathrm{b}}$

\begin{tabular}{|c|c|c|c|c|c|c|c|c|}
\hline Adsorbent & $T \mathrm{~K}$ & $Q_{\max } \mathrm{mg} / \mathrm{g}$ & $\begin{array}{l}\text { Langmuir } \\
\mathrm{K}_{\mathrm{L}} \mathrm{L} / \mathrm{mg}\end{array}$ & $\mathrm{R}_{\mathrm{L}}$ & $\mathrm{R}^{2}$ & $\begin{array}{l}\text { Freundlich } \\
\mathrm{K}_{\mathrm{F}}(\mathrm{mg} / \mathrm{g})(\mathrm{L} / \mathrm{mg})^{1 / \mathrm{n}}\end{array}$ & $1 / n$ & $\mathrm{R}^{2}$ \\
\hline \multirow{4}{*}{ NIPs } & 298 & 36.63 & 0.0094 & 0.4149 to 0.8417 & 0.9273 & 5.9787 & 1.3349 & 0.9391 \\
\hline & 308 & 44.64 & 0.0075 & 0.4706 to 0.8696 & 0.9541 & 4.2338 & 1.2032 & 0.9397 \\
\hline & 318 & 26.16 & 0.0086 & 0.4367 to 0.8532 & 0.9236 & 9.0603 & 1.3326 & 0.9077 \\
\hline & 298 & 123.44 & 0.0092 & 0.4202 to 0.8446 & 0.9999 & 1.5543 & 0.8110 & 0.9964 \\
\hline \multirow{2}{*}{ MIPs } & 308 & 86.73 & 0.0106 & 0.3861 to 0.8251 & 0.9966 & 1.1883 & 0.8350 & 0.9987 \\
\hline & 318 & 64.06 & 0.0120 & 0.3571 to 0.8065 & 0.9954 & 1.0604 & 0.8029 & 0.9983 \\
\hline
\end{tabular}

${ }^{b} \mathrm{Q}_{\max }$, maximum adsorption capacity $(\mathrm{mg} / \mathrm{g}) ; \mathrm{C}_{\mathrm{e}}$, concentration of solution when the adsorption reaches relative equilibrium (mg/L); $\mathrm{K}_{\mathrm{L}}$, Langmuir constant (L/mg); $\mathrm{K}_{\mathrm{F}}$ Freundlich constant; $n$, heterogeneous factor; $\mathrm{R}_{\mathrm{L}}$, separation factor.

Table 3

Adsorption thermodynamic parameters of 2,4-D on SPME coatings.

\begin{tabular}{|c|c|c|c|c|c|c|}
\hline \multirow[t]{2}{*}{ Adsorbent } & \multirow[t]{2}{*}{$C_{0} \mathrm{mg} / \mathrm{L}$} & \multirow[t]{2}{*}{$\triangle H \mathrm{~kJ} / \mathrm{mol}$} & \multirow[t]{2}{*}{$\triangle S \mathrm{~J} /(\mathrm{mol} \cdot \mathrm{K})$} & \multicolumn{3}{|c|}{$\Delta G \mathrm{~kJ} / \mathrm{mol}$} \\
\hline & & & & $298 \mathrm{~K}$ & $308 \mathrm{~K}$ & $318 \mathrm{~K}$ \\
\hline \multirow{4}{*}{ NIPs } & 30 & -4.17 & -10.61 & 1.25 & 1.79 & 1.25 \\
\hline & 70 & -7.29 & -18.85 & 1.02 & 1.54 & 1.02 \\
\hline & 110 & -7.73 & -20.47 & 0.95 & 1.41 & 0.95 \\
\hline & 150 & -7.29 & -19.50 & 2.22 & 2.70 & 2.22 \\
\hline \multirow{6}{*}{ MIPs } & 20 & -15.75 & -52.42 & -0.13 & 0.39 & 0.92 \\
\hline & 50 & -19.46 & -65.99 & 0.21 & 0.86 & 1.52 \\
\hline & 70 & -19.96 & -68.21 & 0.36 & 1.05 & 1.73 \\
\hline & 90 & -18.00 & -62.28 & 0.56 & 1.18 & 1.80 \\
\hline & 110 & -17.28 & -60.13 & 0.64 & 1.24 & 1.84 \\
\hline & 130 & -16.25 & -57.64 & 0.93 & 1.50 & 2.08 \\
\hline
\end{tabular}

c $\Delta G$, free energy $(\mathrm{kJ} / \mathrm{mol}) ; \Delta H$, enthalpy $(\mathrm{kJ} / \mathrm{mol}) ; \Delta S$, entropy $(\mathrm{J} /(\mathrm{mol} \cdot \mathrm{K}))$.

can be obtained $0<R_{\mathrm{L}}<1$, indicating that MIPs and NIPs coating were favorable for $2,4-D$ adsorption. When $1 / n>1$, the adsorption process is not easy to occur, and vice versa. In addition, by fitting the Freundlich model curve, it can be concluded that 2,4-D adsorption on MIPs is easier than on NIPs at the same temperature.

The free energy $\Delta G(\mathrm{~kJ} / \mathrm{mol})$, enthalpy $\Delta H(\mathrm{~kJ} / \mathrm{mol})$ and entropy $\Delta S(\mathrm{~J} /(\mathrm{mol} \cdot \mathrm{K}))$ are usually used to describe the energy change in the adsorption process. The three thermodynamic constants can be calculated by the Eq. (9) and (10), and used to evaluate the adsorption process. Under different concentrations, the linear relation of $\ln K_{\mathrm{d}}$ and $1 / T$ was carried out, $\Delta H$ and $\Delta S$ were calculated respectively by the slope and intercept of the obtained linear equation (Fig. A.8). Then, the Eq. (10), was used to calculate $\Delta G$.

$\ln K_{d}=\frac{\Delta S}{R}-\frac{\Delta H}{R T}=\ln \frac{Q_{e}}{C_{e}}$

$\Delta G=\Delta H-\Delta S T$

in the above equation, $K_{d}$ is the sorption distribution coefficient, $Q_{e}$ is the adsorption capacity at equilibrium $(\mathrm{mg} / \mathrm{g}) ; C_{\mathrm{e}}$ is the equilibrium concentration of the sample solutions $(\mathrm{mg} / \mathrm{L}) ; R$ is ideal gas constant $(\mathrm{R}=8.314 \mathrm{~J} /(\mathrm{mol} \cdot \mathrm{K})) ; T$ is the absolute temperature.

The thermodynamic parameters such as $\Delta G, \Delta H$ and $\Delta S$ are the main characteristics of adsorption process. Langmuir and Freundlich are the most widely used isotherm adsorption models and for calculation of thermodynamic parameters. The adsorption enthalpy $(\Delta H)$, entropy $(\Delta S)$ and free energy $(\Delta G)$ of 2,4-D on SPME coatings are given in Table 3 . The negative value of $\Delta H$ indicates that the adsorption is an exothermic process, and the adsorption capacity is inversely proportional to temperature. The absolute value of $\Delta H$ is lower than $40 \mathrm{~kJ} / \mathrm{mol}$, suggesting that adsorption of 2,4-D on SPME coatings are mainly physical adsorption [36]. The negative $\Delta S$ indicates the disorder degree of the interface between the SPME coatings and 2,4-D solution decreases after adsorption. The diffusion of 2,4-D molecules from solution to SPME coating pores is limited and the degree of freedom is reduced. In addition, adsorption of the SPME coating for 2,4-D is more feasible and spontaneous at lower concentration as $\Delta G$ decreases with the decreasing of the concentration. The value of $\Delta G$ increases with the increasing of temperature, which demonstrates that the increasing of temperature is unfavorable to the 2,4-D adsorption on the SPME coating. It can be seen from the data in Table 3 that the $\Delta G$ value of 2,4-D adsorption on the MIPs coatings is smaller than that on the NIPs coatings. That can prove that the MIPs coating can extract 2,4-D more effectively than NIPs coatings.

\section{Conclusion}

Solid-phase microextraction (SPME) has been applied increasingly for sample preparation due to its easy miniaturization, automation of devices, and its convenience in coupling with chromatographic instruments. Performances of SPME devices depend on the coating adsorption property. Characterization of the adsorption is challenging due to the small size, and fast adsorption kinetics using conventional methods using manual sampling. The main goal of the current study was to design an in-situ adsorption measurement system and evaluate kinetics and thermodynamics of the blade type SPME coating. The research has shown that the system is able to detect the fast adsorption process continuously in only few milliliter adsorption solutions. The pseudo-second-order model is found to be the most suitable for describing 2,4-D adsorption on SPME coating. The thermodynamic parameters $(\Delta H, \Delta S$, $\Delta G$ ) indicate that 2,4-D adsorption at low concentration by the SPME coating is exothermic and spontaneous process. Under the same conditions, MIPs coatings have higher adsorption capacity, and faster adsorption rate than NIPs coating. These findings have significant implications for the understanding of adsorption mechanism of SPME coating. It is also useful for the understanding of the adsorption nature of surface imprinted polymers. However, the scope of this study is limited to only blade type SPME coating and do not include fiber or other type of coatings. In addition, further work needs to be done to explore the effect of coating thickness on the main parameters of adsorption kinetics and thermodynamics.

\section{CRediT authorship contribution statement}

Xiaoxia Yang: Data curation, Writing - original draft, Investigation. Turghun Muhammad: Conceptualization, Methodology, Supervision, Writing - review \& editing. Jingjing Yang: Software. Ayzukram Yasen: Validation. Lingxin Chen: Writing - review \& editing.

\section{Declaration of Competing Interest}

No conflict of interest.

\section{Acknowledgment}

This work was supported by the National Natural Science Foundation of China (21565025). 


\section{Appendix A. Supplementary data}

Supplementary material related to this article can be found, in the online version, at doi:https://doi.org/10.1016/j.sna.2020. 112190.

\section{References}

[1] V.O. Njoku, B.H. Hameed, Preparation and characterization of activated carbon from corncob by chemical activation with $\mathrm{H}_{3} \mathrm{PO}_{4}$ for 2,4-dichlorophenoxyacetic acid adsorption, Chem. Eng. J. 173 (2011) 391-399, http://dx.doi.org/10.1016/j.cej.2011.07.075.

[2] S. Seif, F. Graef, S. Gordon, M. Windbergs, Monitoring drug release from electrospun fibers using an in situ fiber-optic system, Dissolu. Technol. 23 (2016) 6-11, http://dx.doi.org/10.14227/dt230216p6.

[3] F.M. De Souza, O.A.A. Dos Santos, M.G.A. Vieira, Adsorption of herbicide 2,4-D from aqueous solution using organo-modified bentonite clay, Environ. Sci. Pollu. R 26 (2019) 18329-18342, http://dx.doi.org/10.1007/s11356-01905196-W.

[4] J.S. Bus, L.E. Hammond, Regulatory progress, toxicology, and public concerns with 2,4-D: where do we stand after two decades? Crop Prot. 26 (2007) 266-269, http://dx.doi.org/10.1016/j.cropro.2005.06.010.

[5] A.C. Vinayaka, S. Basheer, M.S. Thakur, Bioconjugation of CdTe quantum dot for the detection of 2,4-dichlorophenoxyacetic acid by competitive fluoroimmunoassay based biosensor, Biosens. Bioelectron. 24 (2009) 1615-1620, http://dx.doi.org/10.1016/j.bios.2008.08.042.

[6] M. Rezazadeh, Y. Yamini, S. Seidi, E. Tahmasebi, F. Rezaei, Electromembrane surrounded solid phase microextraction followed by injection port derivatization and gas chromatography-flame ionization detector analysis for determination of acidic herbicides in plant tissue, J. Agr. Food Chem. 62 (2014) 3134-3142, http://dx.doi.org/10.1021/jf500017r.

[7] E. Maloschik, M. Mörtl, A. Székács, Novel derivatisation technique for the determination of chlorophenoxy acid type herbicides by gas chromatography-mass spectrometry, Anal. Bioanal. Chem. 397 (2010) 537-548, http://dx.doi.org/10.1007/s00216-010-3486-1.

[8] M.Z. Hua, S.L. Feng, S. Wang, X.N. Lu, Rapid detection and quantification of 2,4-dichlorophenoxyacetic acid in milk using molecularly imprinted polymers-surface-enhanced Raman spectroscopy, Food Chem. 258 (2018) 254-259, http://dx.doi.org/10.1016/j.foodchem.2018.03.075.

[9] J.L. Qiu, G.S. Chen, H. Zhou, J.Q. Xu, G.F. Ouyang, In vivo tracing of organophosphorus pesticides in cabbage (Brassica parachinensis) and aloe (Barbadensis), Sci. Total Environ. 550 (2016) 1134-1140, http://dx.doi.org/10. 1016/j.scitotenv.2015.11.108.

[10] É.A. Souza-Silva, R. Jiang, A. Rodríguez-Lafuente, E. Gionfriddo, J. Pawliszyn, A critical review of the state of the art of solid-phase microextraction of complex matrices I. Environmental analysis, TrAC Trend. Anal. Chem. 71 (2015) 236-248, http://dx.doi.org/10.1016/j.trac.2015.04.016.

[11] J.P. Ma, R.H. Xiao, J.H. Li, J. Li, B.Z. Shi, Y.J. Liang, et al., Headspace solid-phase microextraction with on-fiber derivatization for the determination of aldehydes in algae by gas chromatography-mass spectrometry, J. Sep. Sci. 34 (2011) 1477-1483, http://dx.doi.org/10.1002/jssc.201000860.

[12] M. Odziemkowski, J.A. Koziel, D.E. Irish, J. Pawliszyn, Sampling and raman confocal microspectroscopic analysis of airborne particulate matter using poly(dimethylsiloxane) solid-phase microextraction fibers, Anal. Chem. 73 (2001) 3131-3139, http://dx.doi.org/10.1021/ac001141m.

[13] K. Alexander, G.-R. Germán Augusto, H. Dietmar, J. Pawliszyn, Breaching the 10 second barrier of total analysis time for complex matrices via automated coated blade spray, Anal. Chem. 91 (2019) 13039-13046, http://dx.doi.org/10. 1021/acs.analchem.9b03225.

[14] N.A. Md, N. Emir, S. Varoon, T. Marcos, J. Pawliszyn, Effect of transport parameters and device geometry on extraction kinetics and efficiency in direct immersion solid-phase microextraction, Anal. Chem. 90 (2018) 11548-11555, http://dx.doi.org/10.1021/acs.analchem.8b02855.

[15] L.X. Chen, X.Y. Wang, W.H. Lu, X.Q. Wu, J.H. Li, Molecular imprinting: perspectives and applications, Chem. Soc. Rev. 45 (2016) 2137-2211, http:// dx.doi.org/10.1039/c6cs00061d.

[16] R.X. Gao, X.R. Mu, J.J. Zhang, Y.H. Tang, Specific recognition of bovine serum albumin using superparamagnetic molecularly imprinted nanomaterials prepared by two-stage core-shell sol-gel polymerization, J. Mater. Chem. B Mater. Biol. Med. 2 (2014) 783-792, http://dx.doi.org/10.1039/c3tb21424a.

[17] J.W. Lowdon, K. Eersels, R. Rogosic, T. Boonen, B. Heidt, H. Diliën, et al., Surface grafted molecularly imprinted polymeric receptor layers for thermal detection of the New Psychoactive substance 2-methoxphenidine, Sensor. Actuat. A: Phys. 295 (2019) 586-595, http://dx.doi.org/10.1016/j.sna.2019.06. 029.

[18] N. Reyes-Garces, E. Gionfriddo, G.A. Gomez-Rios, M.N. Alam, E. Boyaci, B. Bojko, et al., Advances in solid phase microextraction and perspective on future directions, Anal. Chem. 90 (2018) 302-360, http://dx.doi.org/10.1021/ acs.analchem.7b04502.

[19] S.F. Xu, H.Z. Lu, J.H. Li, X.L. Song, A.X. Wang, L.X. Chen, et al., Dummy molecularlyi Imprinted polymers-capped CdTe quantum dots for the fluorescent sensing of 2,4,6-trinitrotoluene, ACS Appl. Mater. Inter. 5 (2013) 8146-8154, http://dx.doi.org/10.1021/am4022076.
[20] P. Stajanca, K. Hicke, K. Krebber, Distributed fiberoptic sensor for simultaneous humidity and temperature monitoring based on polyimide-coated optical fibers, Sensors 19 (2019) 5279-5294, http://dx.doi. org/10.3390/s19235279.

[21] X. Li, Q. Li, H. Zhou, H.X. Hao, T.Z. Wang, S.M. Zhao, et al., Rapid, on-site identification of explosives in nanoliter droplets using a UV reflected fiber optic sensor, Anal. Chim. Acta 751 (2012) 112-118, http://dx.doi.org/10.1016/ j.aca.2012.09.022.

[22] F. Gao, T. Muhammad, M. Bakri, P. Pataer, L.X. Chen, In situ liquid-phase-adsorption measurement system based on fiber-optic sensing with the aid of membranes, ACS Omega 3 (2018) 10891-10897, http://dx.doi. org/10.1021/acsomega.8b01059.

[23] B.H. Hameed, J.M. Salman, A.L. Ahmad, Adsorption isotherm and kinetic modeling of 2,4-D pesticide on activated carbon derived from date stones, J. Hazard. Mater. 163 (2009) 121-126, http://dx.doi.org/10.1016/j.jhazmat. 2008.06.069.

[24] S.A. Zhong, C.Y. Zhou, X.N. Zhang, H. Zhou, H. Li, X.H. Zhu, et al., A novel molecularly imprinted material based on magnetic halloysite nanotubes for rapid enrichment of 2,4-dichlorophenoxyacetic acid in water, J. Hazard. Mater. 276 (2014) 58-65, http://dx.doi.org/10.1016/j.microc.2018. 11.break048.

[25] C. Liu, A.M. Omer, X.K. Ouyang, Adsorptive removal of cationic methylene blue dye using carboxymethyl cellulose/k-carrageenan/activated montmorillonite composite beads: Isotherm and kinetic studies, Int. J. Biol. Macromol. 106 (2018) 823-833, http://dx.doi.org/10.1016/j.ijbiomac.2017.08.084.

[26] R. Li, N. Liang, X.X. Ma, B. Chen, F. Huang, Study on the adsorption behavior of glycerin from fatty acid methyl esters by a tertiary amine-type anion exchange resin, J. Chromatogr. A 1586 (2019) 62-71, http://dx.doi.org/10. 1016/j.chroma.2018.11.079.

[27] F.C. Wu, R.L. Tseng, S.C. Huang, R.S. Juang, Characteristics of pseudo-second-order kinetic model for liquid-phase adsorption: a mini-review, Chem. Eng. J. 151 (2009) 1-9, http://dx.doi.org/10.1016/j.cej. 2009.02.024

[28] F.C. Wu, R.L. Tseng, R.S. Juang, Initial behavior of intraparticle diffusion model used in the description of adsorption kinetics, Chem. Eng. J. 153 (2009) 1-8, http://dx.doi.org/10.1016/j.cej.2009.04.042.

[29] Z.P. Gao, Z.F. Yu, T.L. Yue, S.Y. Quek, Adsorption isotherm, thermodynamics and kinetics studies of polyphenols separation from kiwifruit juice using adsorbent resin, J. Food Eng. 116 (2013) 195-201, http://dx.doi.org/10.1016/j. jfoodeng.2012.10.037.

[30] B. Tanhaei, A. Ayati, M. Lahtinen, M. Sillanpää, Preparation and characterization of a novel chitosan $/ \mathrm{Al}_{2} \mathrm{O}_{3} /$ magnetite nanoparticles composite adsorbent for kinetic, thermodynamic and isotherm studies of Methyl Orange adsorption, Chem. Eng. J. 259 (2015) 1-10, http://dx.doi.org/ 10.1016/j.cej.2014.07.109.

[31] K. Haupt, A. Dzgoev, K. Mosbach, Assay system for the herbicide2,4-Dichlorophenoxyacetic acid using a molecularly imprinted polymer as an artificial recognition element, Anal. Chem. 70 (1998) 628-631, http://dx.doi.org/10.1021/ac9711549.

[32] R.J. Umpleby, S.C. Baxter, Y. Chen, R.N. Shah, K.D. Shimizu, Characterization of molecularly imprinted polymers with the Langmuir-Freundlich isotherm, Anal. Chem. 73 (2001) 4584-4591, http://dx.doi.org/10.1021/ac0105686.

[33] D. Duranoğlu, A.W. Trochimczuk, U. Beker, Kinetics and thermodynamics of hexavalent chromium adsorption onto activated carbon derived from acrylonitrile-divinylbenzene copolymer, Chem. Eng. J. 187 (2012) 193-202, http://dx.doi.org/10.1016/j.cej.2012.01.120.

[34] Y.H. Zhao, Y.Q. Yuan, W.B. Gan, M.H. Yang, Optical fiber fabry-perot humidity sensor based on polyimide membrane: sensitivity and adsorption kinetics, Sensor. Actuat. A: Phys. 281 (2018) 48-54, http://dx.doi.org/10.1016/j.sna. 2018.08.044.

[35] I.A.A. Hamza, B.S. Martincigh, J.C. Ngila, V.O. Nyamori, Adsorption studies of aqueous $\mathrm{Pb}$ (II) onto a sugarcane bagasse/multi-walled carbon nanotube composite, Phys. Chem. Earth (2002) 66 (2013) 157-166, http://dx.doi.org/10. 1016/j.pce.2013.08.006.

[36] C.L. Qi, M.W. Meng, Q.Y. Liu, C.Y. Kang, S.Y. Huang, Z.M. Zhou, et al., Adsorption kinetics and thermodynamics of auramine-O on sugarcane leaf-based activated carbon, J. Disper. Sci. Technol. 36 (2015) 1257-1263, http://dx.doi.org/10.1080/01932691.2014.973036.

\section{Biographies}

Xiaoxia Yang is currently pursuing the master's degree at College of Chemistry and Chemical Engineering, Xinjiang University, China. Her research interests include adsorption kinetics and thermodynamics, fiber-optic sensing, molecularly imprinting polymers (MIPs) coating and chemometrics.

Turghun Muhammad has been a professor at College of Chemistry, Xinjiang University, since 2013. He was a postdoc researcher at Cranfield University (UK) where he worked on molecularly imprinting polymers (MIPs). He was an Erasmus Mundus scholar at department of analytical chemistry, Complutense University (Spain). He received his PhD degree in Xinjiang Medical University (China). He completed his MSc in Dalian University of Technology (China). His research activities include synthesis and application of MIPs, investigation of adsorption kinetics and thermo- 
dynamics, sample preparation techniques, fluorescence technology, flow injection analysis, fiber-optic sensing and sensor chip fabrication.

Jingjing Yang is a master's at College of Chemistry, Xinjiang University, China. Her research interests include fiber-optic sensing, investigation of adsorption kinetics and thermodynamics.

Ayzukram Yasen is a currently pursuing the master's degree at College of Chemistry, Xinjiang university, China. Her research interests include synthesis and application of molecularly imprinting polymers (MIPs), sample preparation techniques and sensor chip fabrication.
Lingxin Chen has been a professor at Yantai Institute of Coastal Zone Research, Chinese Academy of Sciences, since 2009. He obtained his Ph.D. in analytical chemistry at Dalian Institute of Chemical Physics, Chinese Academy of Sciences, in 2003. During 2004 - 2009, he worked at Department of Chemistry, Tsinghua University, and Department of Applied Chemistry, Hanyang University, respectively. His research interests include the studies of novel properties of materials such as functionalized nanoparticles \& functional probe molecules for developing nanoscale biochemica analysis methods and molecular imprinting-based sample pretreatment technology. 